\title{
ÍNDICE DE ÁREA FOLIAR E ALTURA DE PLANTAS DE ARROZ SUBMETIDAS A DIFERENTES PRÁTICAS DE MANEJO ${ }^{1}$
}

\author{
Reimar Carlesso ${ }^{2}$, Marcos Gregório Ramos Hernandez ${ }^{3}$, Afranio Almir Righes ${ }^{2}$ \\ e Sidnei Osmar Jadoski ${ }^{4}$
}

\begin{abstract}
RESUMO
Este trabalho teve como objetivo avaliar o efeito de diferentes níveis de manejo da água de irrigação, os sistemas de preparo do solo e herbicidas, no índice de área foliar e na altura de plantas do arroz irrigado por inundação. O experimento foi conduzido no ano agrícola 1993/1994, em área da Universidade Federal de Santa Maria, Santa Maria, RS. A cultivar de arroz BR-IRGA-414 foi semeada em linha, em 22 de dezembro de 1993 e o delineamento experimental foi em blocos ao acaso, trifatorial $\left(2^{3}\right)$ constituído de duas épocas de início da irrigação (15 e 30 dias após a emergência), dois sistemas de preparo do solo (convencional e mínimo) e dois níveis de controle de plantas invasoras (com e sem uso de herbicidas). As épocas de início da irrigação influenciaram no índice de área foliar na fase vegetativa e no final do ciclo da cultura, e a altura das plantas, nas fases vegetativa e de floração. $O$ início da irrigação aos 15 dias após a emergência das plantas proporcionou maior índice de área foliar e altura de plantas, ocasionando maior área fotossinteticamente ativa na fase inicial de desenvolvimento. O sistema de cultivo mínimo proporcionou, na fase vegetativa, maior altura de plantas em relação ao sistema convencional.
\end{abstract}

Palavras-chave: Oryza sativa L, irrigação, preparo do solo, herbicida, altura de plantas

\section{LEAF AREA INDEX AND PLANT HEIGHT OF RICE SUBMITTED TO DIFFERENT CULTURAL PRACTICES}

\begin{abstract}
The objective of this experiment was to study the effect of different water management, tillage systems and weed control on leaf area index and plant height of irrigated rice. The experiment was conducted during the 1993/94 crop growing season in the Rural Engineering Department Experimental Field at the Federal University of Santa Maria, Santa Maria - RS. The rice cultivar, BR-IRGA-414, was sown on December 22, 1993 in rows spaced $0.16 \mathrm{~m}$ apart, using 124 seeds $/ \mathrm{m}$. A factorial $\left(2^{3}\right)$ experiment in a completely randomized block design was used. Two irrigation dates (15 and 30 days after emergence); two tillage system (minimum and conventional) and two weed control levels (with and without chemical application) were tested. Differences in rice leaf area index were observed between the two irrigation dates during the beginning of the vegetative stage and near the end of grain maturation. However, differences in plant height were observed during vegetative and flowering stages. Plant leaf area was larger at the beginning of the vegetative stage for plants that received irrigation at 15 days after emergency. Rice plants cultivated in the minimum tillage system resulted in higher plant height than those cultivated with conventional tillage.
\end{abstract}

Key words: Oryza sativa $L$, irrigation, cultivation, herbicides, plant height

\footnotetext{
${ }^{1}$ Financiado pela Fundação de Amparo à Pesquisa do Estado do Rio Grande do Sul

${ }^{2}$ Engenheiro Agrônomo, PhD., Professor Titular do Departamento de Engenharia Rural, Universidade Federal de Santa Maria, CEP 97105-900 Santa Maria, RS, bolsista do CNPq.

${ }^{3}$ Engenheiro Agrônomo, MS., Professor de Agricultura no Colégio Agrícola de São Vicente do Sul

${ }^{4}$ Aluno do Programa de Pós-Graduação em Engenharia Agrícola da UFSM
} 


\section{INTRODUÇÃO}

As práticas de manejo das culturas afetam a capacidade produtiva, que pode ser avaliada através da análise na taxa de crescimento e desenvolvimento das plantas (Kvet et al., 1971). De acordo com Lucchesi (1984) índices morfofisiológicos, como o índice de área foliar e a altura de plantas, constituem-se em um complemento da análise quantitativa do crescimento vegetal, possibilitando a determinação dos efeitos da utilização de diferentes manejos da cultura.

De acordo com Ferraz (1983) plantas de arroz de menor porte, com reduzida área foliar e baixo perfilhamento, são normalmente encontradas em áreas submetidas a deficiência de água no solo, nas fases iniciais do ciclo de desenvolvimento das plantas podendo, segundo Fageria (1984) haver redução do número de panículas por metro quadrado; entretanto, a partir do perfilhamento das plantas e quando a irrigação por inundação for mantida conforme a recomendação, o rendimento de grãos não será seriamente afetado (Ferraz, 1983). Segundo Murty \& Kamakrisnayha (1982) a deficiência de água no solo, após a emergência, provoca redução na altura das plantas e no prolongamento do período de crescimento vegetativo; no entanto, os autores consideram a fase de diferenciação do primórdio floral como o período mais crítico para a ocorrência da deficiência de água no solo.

A antecipação do início da irrigação, de 35 para 15 dias após a emergência das plantas (DAE) (Wielewicki et al., 1997) ou o fornecimento de água por maior período de tempo durante o ciclo da cultura do arroz (Giudice, 1983) são estratégias que proporcionam maior absorção de nutrientes e maior produção de massa seca da parte aérea das plantas. $\mathrm{O}$ atraso no início da irrigação da cultura do arroz, segundo Noldin (1988) reduziu o rendimento de grãos e aumentou de 3,3 para $40 \%$, a população de plantas de arroz vermelho. Por outro lado, Carvalho \& Alcântara (1990) salientam que o controle das plantas invasoras representa uma atividade importante na produção do arroz, uma vez que estas competem em água, luz, nutrientes do solo e gás carbônico, com as plantas cultivadas.

O sistema de preparo reduzido do solo, como cultivo mínimo ou plantio direto, segundo Oliveira et al. (1994) é uma opção utilizada pelos produtores do Estado do Rio Grande do Sul, para reduzir as crescentes infestações de plantas invasoras, principalmente o arroz vermelho. Mello (1995) relata que em 1995 o arroz irrigado ocupou uma área de aproximadamente 950 mil hectares no Estado do Rio Grande do Sul, dos quais se calcula que na safra 93/94, pelo menos 240 mil hectares utilizaram alguma forma de cultivo mínimo ou plantio direto. Menezes, citado por Bizzi (1994) não observou diferenças no rendimento de grãos do arroz com a utilização do cultivo mínimo ou convencional.

Maior altura em plantas de arroz foi observada por Oliveira et al. (1994) em áreas cultivadas com preparo convencional em relação ao cultivo mínimo; no entanto, Silva et al., citados por Bizzi (1994) constataram diferenças significativas na altura de plantas e no índice de área foliar de plantas de arroz submetidas ao sistema de preparo do solo convencional e do cultivo mínimo. Andrade et al. (1997) verificaram que a deficiência de potássio no solo reduziu a altura de plantas de arroz. A combinação do herbicida Glyphosate com Pendimethalin, aplicados antes e após a semeadura do arroz, segundo Abud (1994) controlou satisfatoriamente as plantas invasoras, não tendo sido constatados efeitos que pudessem influir negativamente no crescimento das plantas de arroz.

Ante a importância que o arroz irrigado tem para o Rio Grande do Sul, o objetivo deste trabalho foi avaliar o efeito de diferentes níveis de manejo da água de irrigação, os sistemas de preparo do solo e de controle de plantas invasoras no índice de área foliar e a altura de plantas de arroz irrigado por inundação.

\section{MATERIAL E MÉTODOS}

O experimento foi realizado em área do Departamento de Engenharia Rural da Universidade Federal de Santa Maria, Santa Maria, RS. O solo do local é classificado como Planossolo ou Abaqualf (Brasil, 1973) e o experimento foi instalado em 22 de dezembro de 1993, utilizando-se a cultivar de arroz irrigado, BR-IRGA-414, a semeadura foi realizada com a semeadora TD-300A (Semeato) com densidade de 124 sementes por metro linear e espaçamento entre linhas de $0,16 \mathrm{~m}$.

$\mathrm{O}$ delineamento experimental foi em blocos ao acaso, trifatorial $\left(2^{3}\right)$ com três repetições, a dimensão de cada parcela experimental foi de $10 \times 12 \mathrm{~m}$ e os tratamentos constituíram-se de duas épocas de início da irrigação (15 e $30 \mathrm{DAE})$, dois sistemas de preparo do solo (convencional e cultivo mínimo) e duas práticas de controle de plantas invasoras (com e sem herbicida); os herbicidas utilizados foram o Propanil com a dose de 10,0 $\ell$ ha $^{-1}$ e Quinclorac - Facet 50PM, com a dosagem de $0,750 \mathrm{~kg} \cdot \mathrm{ha}^{-1}$.

No sistema convencional, o preparo do solo foi realizado através de uma gradagem aradora e de duas gradagens de nivelamento e, no cultivo mínimo, através de uma gradagem realizada 45 dias antes da semeadura, seguida de pousio e de aplicação de herbicida de ação total (Glyphosate 1,08 (ia) kg.ha- ${ }^{-1} \mathrm{e}$ "Roundup" 3,0 $\ell \cdot$ ha $^{-1}$ ) anterior à semeadura. Nos tratamentos de controle de plantas invasoras os herbicidas Propanil e Facet foram aplicados no dia 29 de dezembro de 1993, independentemente da época de início de irrigação.

A adubação de manutenção foi baseada na análise do solo, seguindo-se a recomendação da Comissão de Fertilidade do Solo - RS/SC (1989). Utilizaram-se 10kg de N.ha ${ }^{-1}$, 20kg de P.ha ${ }^{-1} \mathrm{e}$ $60 \mathrm{~kg}$ de K.ha ${ }^{-1}$, aplicados por ocasião da semeadura. A adubação de cobertura com $35 \mathrm{~kg}$ de N.ha- ${ }^{-1}$, na forma de uréia, foi aplicada a lanço, aos 54 DAE.

A irrigação foi realizada por inundação contínua, mantendo-se lâmina média de água de $10 \mathrm{~cm}$; a manutenção da água, em cada parcela, foi realizada através de um sistema de abastecimento de água sob pressão, com controle automático do nível, através de válvulas-bóia.

Após a emergência, três plantas por parcela foram identificadas, marcadas e submetidas à avaliações não destrutivas da área foliar, senescência e altura de plantas, desde a emissão da terceira folha até a emissão da folha bandeira, aproximadamente duas vezes por semana. A área foliar de cada folha foi calculada através do produto das medidas de seu comprimento e largura, multiplicadas pelo coeficiente de 0,75 . As observações de senescência foram realizadas visualmente, estabelecendo-se uma escala de 0 a $100 \%$, que correspondia às folhas totalmente verdes e totalmente senescentes, respectivamente. A altura de plantas foi determinada com régua, medindo-se a distância entre o nível de solo e a bainha foliar mais alta da planta. 
Na colheita coletaram-se panículas das plantas de arroz em uma área de $4,0 \mathrm{~m}^{2}$ de cada unidade experimental e as amostras foram trilhadas e os grãos secados ao sol. A determinação da umidade dos grãos foi realizada com o auxílio do determinador de umidade de grãos "DOLE 400, Moisture Tester E.T.N.", enquanto o rendimento de grãos foi calculado com base na umidade dos grãos a $13 \%$.

Os resultados foram submetidos a análise estatística, utilizando-se o programa Statistical Analysis System (SAS) e o Sistema para Análises Estatísticas - SAEG V 4.0. Determinouse a análise da variância e as médias dos tratamentos foram comparadas em nível de 5\% de probabilidade, através dos testes F e de Tukey.

\section{RESULTADOS E DISCUSSÃO}

Diferenças significativas para o índice de área foliar foram observadas para os níveis de irrigação, preparo do solo e interação tripla entre a irrigação $\mathrm{x}$ preparo do solo $\mathrm{x}$ herbicidas (Tabela 1). O índice de área foliar das plantas de arroz foi maior durante a fase de crescimento vegetativo com o início da irrigação aos 15 DAE (Tabela 2); entretanto, após a maturação fisiológica das plantas maior índice de área foliar foi observado nas plantas que receberam irrigação aos 30 DAE, cujos resultados indicam que a antecipação da irrigação proporcionou maior crescimento vegetativo das plantas de arroz na fase inicial de desenvolvimento, favorecendo o estabelecimento da cultura.
O menor índice de área foliar observado após a maturação fisiológica das plantas submetidas ao início da irrigação aos 15 DAE, foi devido à maior senescência das folhas, porém o rendimento de grão das plantas submetidas ao início da irrigação aos 15 DAE (5.929 kg.ha-1) foi 17,9\% maior do que quando a irrigação se iniciou aos $30 \mathrm{DAE}\left(5.030 \mathrm{~kg} \cdot \mathrm{ha}^{-1}\right)$. Estes resultados concordam com Castillo et al. (1992) que relataram diminuição no rendimento de grãos e produção de matéria seca da parte aérea das plantas de arroz, quando se suprimiu a irrigação de 15 a 35 dias após a implantação da cultura; entretanto, Aragon et al. citados por Castillo et al. (1992) observando os efeitos do déficit hídrico durante o crescimento vegetativo do arroz, e Wielewicki (1997) estudando o comportamento da cultura com início da irrigação aos 15 ou 35 DAE, não verificaram redução no rendimento de grãos do arroz.

A utilização do preparo convencional ou do cultivo mínimo do solo não ocasionou alterações no índice de área foliar das plantas de arroz durante os períodos de crescimento vegetativo, diferenciação do primórdio floral e floração (Tabela 1) mas a partir da maturação fisiológica das plantas foi observado maior índice de área foliar nas plantas cultivadas com o preparo mínimo do solo; entretanto, o maior índice de área foliar não ocasionou incremento no rendimento de grãos das plantas de arroz.

A interação entre os níveis de irrigação, preparo do solo e herbicidas, indicou maior área foliar das plantas de arroz, no período inicial de desenvolvimento das plantas, quando a irrigação se iniciou aos 15 DAE; resultados similares foram

Tabela 1. Quadrado médio do índice de área foliar e altura de plantas de arroz, variedade BR-IRGA-414, durante o ciclo da cultura, submetida a dois níveis de irrigação, preparos do solo e herbicidas

\begin{tabular}{|c|c|c|c|c|c|c|c|c|c|c|c|c|}
\hline \multirow{3}{*}{$\begin{array}{c}\text { Causas } \\
\text { de } \\
\text { Variação }\end{array}$} & \multirow[b]{3}{*}{ GL } & \multicolumn{3}{|c|}{ Fase vegetativa } & DPF & \multicolumn{3}{|c|}{.Floração } & \multicolumn{3}{|c|}{ Maturação fisiológica } & \multirow{3}{*}{$\begin{array}{c}\text { Colheita } \\
117\end{array}$} \\
\hline & & \multicolumn{10}{|c|}{$\overline{\text { Dias após a emergência das plântulas }(\mathrm{DAE})}$} & \\
\hline & & \multicolumn{2}{|r|}{27} & 31 & 53 & 73 & 83 & 87 & 102 & 105 & 108 & \\
\hline Blocos & 2 & $0,012 \mathrm{~ns}$ & $0.015 \mathrm{~ns}$ & $0,049 \mathrm{~ns}$ & $0,210 \mathrm{~ns}$ & $0,125 \mathrm{~ns}$ & $0,530 \mathrm{~ns}$ & $0,534 \mathrm{~ns}$ & $0,192 \mathrm{~ns}$ & $0,160 \mathrm{~ns}$ & $0,310 \mathrm{~ns}$ & $0,117 \mathrm{~ns}$ \\
\hline Irrigação (I) & 1 & $0,456 *$ & $0,480 *$ & $0,721 *$ & $0,310 \mathrm{~ns}$ & $0,224 \mathrm{~ns}$ & $1,200 \mathrm{~ns}$ & $1,197 \mathrm{~ns}$ & $0,889 *$ & $0,972 *$ & $1,270 *$ & $1,696 *$ \\
\hline Prep. solo (P) & 1 & $0,081 \mathrm{~ns}$ & $0,157 \mathrm{~ns}$ & $0,170 \mathrm{~ns}$ & $0,697 \mathrm{~ns}$ & $1,251 \mathrm{~ns}$ & $1,060 \mathrm{~ns}$ & $1,058 \mathrm{~ns}$ & $1,420 *$ & $2,024 *$ & $2,450 *$ & $1,904 *$ \\
\hline $\mathrm{I}^{*} \mathrm{P}$ & 1 & $0,036 \mathrm{~ns}$ & $0,130 \mathrm{~ns}$ & $0,088 \mathrm{~ns}$ & $0,021 \mathrm{~ns}$ & $0,173 \mathrm{~ns}$ & $0,079 \mathrm{~ns}$ & $0,079 \mathrm{~ns}$ & $0,000 \mathrm{~ns}$ & $0,000 \mathrm{~ns}$ & $0,012 \mathrm{~ns}$ & $0,052 \mathrm{~ns}$ \\
\hline I*H & 1 & $0,051 \mathrm{~ns}$ & $0,000 \mathrm{~ns}$ & $0,088 \mathrm{~ns}$ & $0,200 \mathrm{~ns}$ & $0,054 \mathrm{~ns}$ & $0,047 \mathrm{~ns}$ & $0,047 \mathrm{~ns}$ & $0,000 \mathrm{~ns}$ & $0,017 \mathrm{~ns}$ & $0,013 \mathrm{~ns}$ & $0,062 \mathrm{~ns}$ \\
\hline $\mathrm{P} * \mathrm{H}$ & 1 & $0,010 \mathrm{~ns}$ & $0,032 \mathrm{~ns}$ & $0,001 \mathrm{~ns}$ & $0,038 \mathrm{~ns}$ & $0,120 \mathrm{~ns}$ & $0,075 \mathrm{~ns}$ & $0,075 \mathrm{~ns}$ & $0,002 \mathrm{~ns}$ & $0,061 \mathrm{~ns}$ & $0,088 \mathrm{~ns}$ & $0,160 \mathrm{~ns}$ \\
\hline $\mathrm{I}^{*} \mathrm{P} * \mathrm{H}$ & 1 & $0,298 *$ & $0,027 \mathrm{~ns}$ & $0,056 \mathrm{~ns}$ & $0,956 \mathrm{~ns}$ & $2,600 \mathrm{~ns}$ & $1,930 *$ & $1,930 *$ & $0,420 \mathrm{~ns}$ & $0,657 \mathrm{~ns}$ & $0,580 *$ & $0,897 *$ \\
\hline Resíduo & 14 & 0,054 & 0,050 & 0,092 & 0,670 & 0,740 & 0,360 & 0,360 & 0,160 & 0,190 & 0,125 & 0,130 \\
\hline \multicolumn{13}{|c|}{ Altura de plantas $(\mathrm{cm})$} \\
\hline Irrigação (I) & 1 & $80,777 *$ & $65,803 *$ & $24,482 *$ & $3,596 \mathrm{~ns}$ & $206,55 *$ & $4,343 \mathrm{~ns}$ & & & & & \\
\hline Prep, Solo(P) & 1 & $0,586 \mathrm{~ns}$ & $6,080 \mathrm{~ns}$ & $0,528 \mathrm{~ns}$ & $5,714 \mathrm{~ns}$ & $45,45 \mathrm{~ns}$ & $5,694 \mathrm{~ns}$ & & & & & \\
\hline Herbicida $(\mathrm{H})$ & 1 & $0,008 \mathrm{~ns}$ & $0,443 \mathrm{~ns}$ & $0,060 \mathrm{~ns}$ & $1,211 \mathrm{~ns}$ & $49,335 \mathrm{~ns}$ & $29,994 \mathrm{~ns}$ & & & & & \\
\hline $\mathrm{I}^{*} \mathrm{P}$ & 1 & $1,202 \mathrm{~ns}$ & $1,696 \mathrm{~ns}$ & $0,132 \mathrm{~ns}$ & $0,005 \mathrm{~ns}$ & $9,089 \mathrm{~ns}$ & $0,599 \mathrm{~ns}$ & & & & & \\
\hline I*H & 1 & $0,162 \mathrm{~ns}$ & $0,346 \mathrm{~ns}$ & $2,496 \mathrm{~ns}$ & $7,271 \mathrm{~ns}$ & $0,525 \mathrm{~ns}$ & $0,023 \mathrm{~ns}$ & & & & & \\
\hline $\mathrm{P} * \mathrm{H}$ & 1 & $0,618 \mathrm{~ns}$ & $1,297 \mathrm{~ns}$ & $8,520 *$ & $12,98 *$ & $119,53 *$ & $13,425 \mathrm{~ns}$ & & & & & \\
\hline $\mathrm{I} * \mathrm{P} * \mathrm{H}$ & 1 & $0,086 \mathrm{~ns}$ & $0,528 \mathrm{~ns}$ & $0,836 \mathrm{~ns}$ & $0,113 \mathrm{~ns}$ & $0,780 \mathrm{~ns}$ & $0,746 \mathrm{~ns}$ & & & & & \\
\hline Resíduo & 14 & 1,078 & 1,280 & 0,907 & 2,258 & 20,490 & 6,580 & & & & & \\
\hline $\mathrm{CV}(\%)$ & & 11,197 & 9,869 & 6,570 & 6,490 & 9,240 & 4,510 & & & & & \\
\hline
\end{tabular}

$\mathrm{DPF}=$ Diferenciação do primórdio floral; $\mathrm{GL}=$ graus de liberdade; $\mathrm{CV}=$ coeficiente de variação; ns = não significativo pelo teste $\mathrm{F}$ em nível de $5 \%$ de probabilidade; * = significativo pelo teste $\mathrm{F}$ a nível de $5 \%$ de probabilidade 
Tabela 2. Valores médios* do índice de área foliar de plantas de arroz, cultivar BR-IRGA-414, em função da época do início da irrigação aos 15 e 30 dias após a emergência e dos preparos do solo

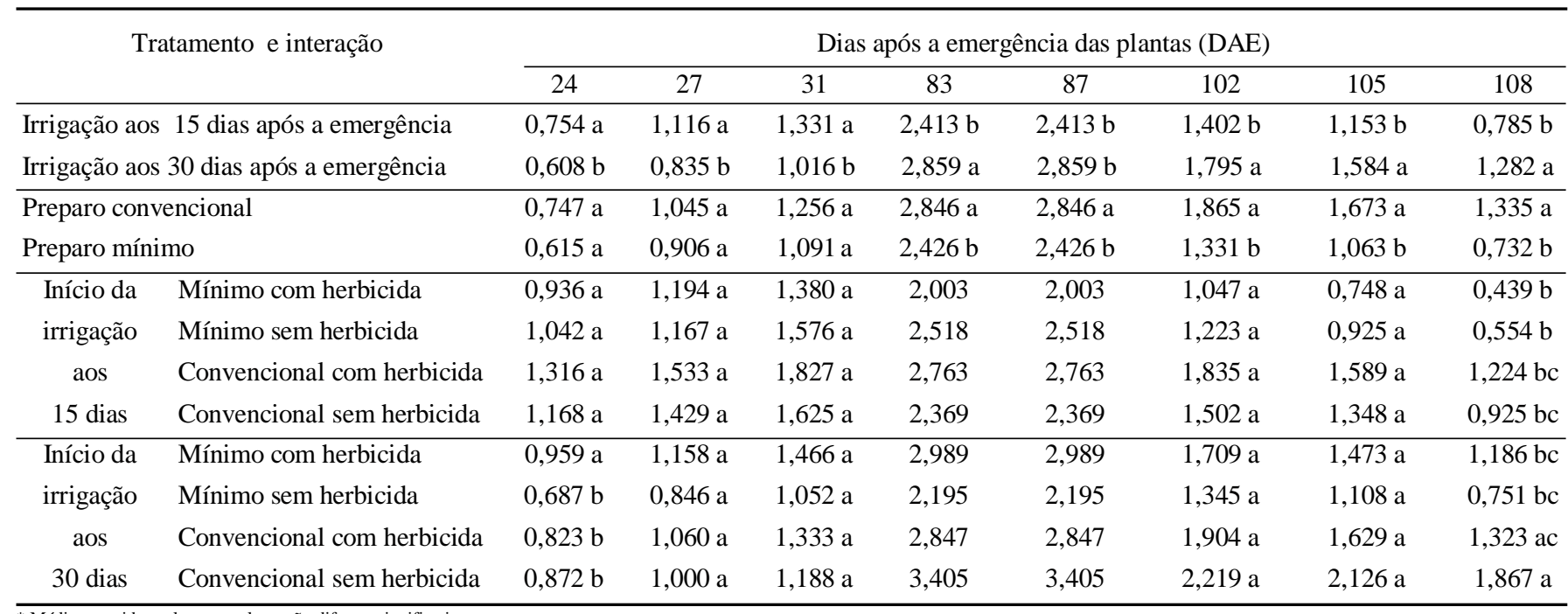

* Médias seguidas pela mesma letra não diferem significativamente

também observados com a utilização do preparo mínimo do solo, herbicidas e início da irrigação aos 30 DAE e indicam, também, que o retardamento do início da irrigação é um dos principais fatores causadores de redução no índice de área foliar durante o estabelecimento da cultura. Cruz et al. (1986) observaram redução no índice de área foliar e na altura de plantas para períodos de baixa disponibilidade hídrica durante o crescimento vegetativo da cultura do arroz.

Diferenças significativas na altura das plantas foram observadas entre os níveis de irrigação e a interação entre o preparo do solo e herbicidas (Tabela 1) cujos resultados indicam que a antecipação da irrigação, de 30 para 15 DAE, ocasiona maior altura das plantas no período inicial de estabelecimento da cultura sem, no entanto, apresentar diferenças após o florescimento.

A interação observada entre o preparo do solo e os herbicidas sinaliza que a utilização do preparo convencional sem o uso de herbicidas ocasiona redução na altura das plantas (Tabela 3) mas antes do florescimento e com a emissão da panícula, a diferença foi reduzida, podendo ter como causa a maior competição das plantas de arroz com as plantas invasoras. Segundo Marchezan (1994) o rápido crescimento inicial de cultivares de arroz é uma característica desejável, principalmente em sistema de cultivo mínimo ou plantio direto, propiciando às plantas de arroz melhores condições na competição inicial com as plantas daninhas. Analisando o comportamento da aplicação seqüencial de herbicidas dessecantes (sulfosate e paraquat) no sistema de cultivo mínimo de arroz irrigado, Pinto et al. (1997) constataram que a altura média de plantas aos 30 DAE foi $22 \%$ superior em relação às plantas cultivadas em área não tratada com herbicida dessecante.

Não foram observadas diferenças no rendimento de grãos com a utilização ou não de herbicidas associados ao preparo convencional ou mínimo do solo, porém o rendimento de grãos foi inferior com a utilização do preparo convencional do solo sem o uso de herbicidas, o que, provavelmente, está associado ao maior revolvimento do solo por ocasião da semeadura favorecendo, assim, a emergência de plantas invasoras.

Os resultados do rendimento de grãos de arroz apresentaram interações significativas entre os tratamentos de épocas de início da irrigação x sistemas de preparo do solo, épocas de início da irrigação x níveis de controle de plantas invasoras e sistemas de preparo do solo $\mathrm{x}$ controle de plantas invasoras. A utilização do preparo convencional do solo e irrigação aos 15 DAE ocasionou aumento de 28,9\% no rendimento de grãos (6056 kg.ha-1) em relação ao início da irrigação aos 30 DAE (4697 kg/ha); resultados semelhantes foram observados também por Gomes et al. (1983) com a cultivar Bluebelle. A utilização de herbicidas com início da irrigação aos 15 DAE proporcionou rendimento

Tabela 3. Valores médios da altura de plantas de arroz*, cultivar BR-IRGA-414, em função da época do início da irrigação aos 15 e 30 dias após a emergência

\begin{tabular}{|c|c|c|c|c|c|}
\hline \multirow{2}{*}{ Tratamento e interação } & \multicolumn{5}{|c|}{ Dias após a emergência das plantas (DAE) } \\
\hline & 24 & 27 & 31 & 53 & 73 \\
\hline Irrigação aos 15 dias após a emergência & $13,24 \mathrm{a}$ & $14,97 \mathrm{a}$ & $16,38 \mathrm{a}$ & $32,01 \mathrm{a}$ & $54,33 \mathrm{a}$ \\
\hline Irrigação aos 30 dias após a emergência & $10,24 \mathrm{~b}$ & $13,03 \mathrm{~b}$ & $15,56 \mathrm{~b}$ & $28,19 \mathrm{a}$ & $51,94 \mathrm{~b}$ \\
\hline Preparo mínimo com herbicida & $11,74 \mathrm{a}$ & $13,99 \mathrm{a}$ & $15,69 \mathrm{a}$ & $28,30 \mathrm{~b}$ & $49,43 \mathrm{~b}$ \\
\hline Preparo convencional com herbicida & $11,86 \mathrm{a}$ & $14,14 \mathrm{a}$ & $16,19 \mathrm{a}$ & $32,57 \mathrm{a}$ & 54,38 a \\
\hline Preparo convencional sem herbicida & $11,09 \mathrm{a}$ & $13,22 \mathrm{a}$ & $15,33 \mathrm{~b}$ & $29,44 \mathrm{~b}$ & $53,73 \mathrm{a}$ \\
\hline
\end{tabular}


de grãos de 6189 kg.ha-1 ${ }^{-1}$ 29,6\% superior em relação ao início da irrigação aos 30 DAE (4777 kg.ha- $\left.{ }^{-1}\right)$.

$\mathrm{O}$ rendimento de grãos da cultura do arroz cultivada sob cultivo mínimo do solo não foi afetado significativamente, quando associado às épocas de início da irrigação e aos níveis de controle de plantas invasoras. Esses resultados indicam que a utilização do cultivo mínimo possibilita redução na quantidade de herbicida a ser utilizada. O início da irrigação aos 30 DAE, associada ao cultivo mínimo do solo, proporcionou um rendimento de grãos de $5363 \mathrm{~kg} \cdot \mathrm{ha}^{-1}, 14,17 \%$ maior do que quando associado ao preparo convencional do solo (4697 kg.ha $\left.{ }^{-1}\right)$ e o rendimento de grãos foi $10,6 \%$ superior com a utilização de herbicidas no controle das plantas invasoras; entretanto, é importante salientar que a infestação de plantas invasoras observadas na área experimental foi inferior à normalmente observada em áreas cultivadas com arroz na região.

\section{CONCLUSÕES}

1. O início de irrigação aos 15 dias após a emergência das plantas de arroz irrigado por inundação proporciona maior dossel vegetativo das plantas, com conseqüente maior área fotossinteticamente ativa na fase inicial de desenvolvimento.

2. O sistema de preparo do solo mínimo ou convencional não ocasiona, nas plantas de arroz irrigado, durante a fase de desenvolvimento vegetativo, alterações no índice de área foliar.

3. O atraso na época do início da irrigação, de 15 para 30 dias após a emergência das plantas de arroz irrigadas por inundação sem a aplicação de herbicidas, reduz o índice de área foliar na fase inicial de desenvolvimento da cultura do arroz.

\section{REFERÊNCIAS BIBLIOGRÁFICAS}

ABUD, J.K. Efeitos da combinação dos herbicidas glyphosate e pendimethalin, antes e após a semeadura do arroz, no sistema de cultivo mínimo, no controle do arroz vermelho (Oryza sativa L.) e capim arroz (Echinochloa crusgalli L.

Beauv). Lavoura Arrozeira Porto Alegre, v.47, n.414, 1994. ANDRADE, W.E.B.; SOUZA, A.F.; CARVALHO, J. G. de. Limitações nutricionais para a cultura do arroz irrigado em solo orgânico da região norte fluminense. Revista Brasileira de Ciência de Solo, Viçosa, v.21, p.513-517, 1997.

BIZZI, A.F. Alternativas de controle de arroz vermelho e capim arroz na cultura do arroz irrigado. Santa Maria: UFSM, 1994. 80p. Dissertação Mestrado

BRASIL. Levantamento de reconhecimento dos solos do

Estado do Rio Grande do Sul. Recife, PE, Ministério da Agricultura, Departamento de Pesquisa Agropecuária Divisão de Pesquisa Pedológica, 1973. 431p. (Boletim Técnico, 30).

CARVALHO, D.A.; ALCÂNTARA, E.N. de. Plantas invasoras da cultura do arroz na zona da mata, Minas Gerais. Pesquisa Agropecuária Brasileira, Brasília, v.25, n.1, p. 25-28, 1990. CATILLO E.G.; BURESH, R.; INGRAM, J.K. Lowland rice yield affected by timing of water deficit and nitrogen fertilization. Agronomy Journal, Madison, v.84, n.2, p. 152159, 1992.

COMISSÃO DE FERTILIDADE DO SOLO-RS/SC. Recomendação da adubação e calagem para os Estados do Rio Grande do Sul e Santa Catarina. 2.ed. Passo Fundo: SBCS - Núcleo Regional Sul/EMBRAPA-CNPT, 1989. 128p.

CRUZ, R.J.; O'TOOLE, J.C.; DRINGKUHN, M.; YAMBAO, E.B.; THANGARAJ, M.; DATTA, S.K. Shoot and root response to water deficits in rainfed lowland rice. Australian Journal Plant Physiology, v.13, p.567-575, 1986.

FAGERIA, N.K. Adubação e nutrição mineral da cultura do arroz. Rio de Janeiro: SNLCS, 1984. 228p.

FERRAZ, E.C. Fisiologia da cultura do arroz. In: SIMPÓSIO SOBRE A CULTURA DO ARROZ DE SEQUEIRO, 1983, Jaboticabal. Anais... Piracicaba: Instituto da Potassa, 1983. p.77-90.

GIUDICE, M. DEL Absorção cumulativa de nutrientes minerais em duas variedades de arroz (Oryza sativa $\mathbf{L}$.) cultivadas em três diferentes níveis de disponibilidade de água. Campinas: Fundação Cargill, 1983. 110p.

GOMES, A.; PAULETTO, E.A.; TURATTI, A.L.; VAHL, L.C. Manejo da água em arroz irrigado. I - Cultivar Bluebelle. In: REUNIÃO DA CULTURA DO ARROZ IRRIGADO, 12., 1983. Porto Alegre. Anais... Porto Alegre. IRGA 1983. p.159-163.

KVET, J.; ONDOK, J.P.; NECAS, J.; JARVIS, P.G. Methods of growth analysis. In: SESTAK, Z. et.al. Plant photosynthetic production; manual of methods. Haia: Dr. W. Junk N.V. Publishers, 1971. p.343-91.

LUCCHESI, A.A. Utilização prática da análise de crescimento vegetal. Anais... da E.S.A. "Luiz de Queiroz", n.41, p.181202, 1984.

MARCHEZAN, E. Arroz vermelho, caracterização prejuízos e controle. Ciência Rural, Santa Maria, v.24. n.2, p.415-421, 1994.

MELLO, I. Plantio direto de arroz irrigado no sul do Brasil. Lavoura Arrozeira, Porto Alegre, v.48, n.422. p. 3-8, 1995.

MURTY, K.S.; KAMAKRISNAYHA, G. Shoot characteristics of rice crop with emphasis on rice. Los Bãnos: International Rice Research Institute, 1982. p. 145-152.

NOLDIN, J.A. Controle de arroz vermelho no sistema de semeadura em solo inundado. Lavoura Arrozeira, Porto Alegre, v.41, n.377, p. 11-13, 1988.

OLIVEIRA, J.C.S.; MARCHEZAN, E.; STORCK, L.; MACHADO, S. L. O. Sistemas de preparo do solo para o arroz irrigado (Oryza sativa L.) Ciência Rural, Santa Maria, v.24, n.3, p. 489-493, 1994.

PINTO, J.J.O.; SCHRÖDER, E.P.; SILVA, O. S.; AGOSTINETTO, D. Comportamento de herbicidas dessecantes no sistema de cultivo mínimo de arroz irrigado, In: REUNIÃO DA CULTURA DE ARROZ IRRIGADO, 22., 1997. Camburiú, SC. Anais...

WIELEWICKI, A. Eficiência de calagem em arroz sob duas épocas de início da irrigação. Santa Maria: UFSM, 1997. 98p. Dissertação Mestrado

WIELEWICKI, A.; MARCHEZAN, E.; STORCK, L. Absorção de nutrientes pelo arroz em resposta à calagem e à época de início da irrigação. Ciência Rural, Santa Maria, v.28, n.1, p.17-21, 1998. 